\title{
Optimization on Emergency Resources Transportation Network Based on Bayes Risk Function: A Case Study
}

\author{
Changfeng Zhu, ${ }^{1}$ Gang Fang, ${ }^{1}$ and Qingrong Wang ${ }^{2}$ \\ ${ }^{1}$ School of Traffic and Transportation, Lanzhou Jiaotong University, Lanzhou 730070, China \\ ${ }^{2}$ School of Electronic and Information Engineering, Lanzhou Jiaotong University, Lanzhou 730070, China \\ Correspondence should be addressed to Changfeng Zhu; cfzhu003@163.com
}

Received 27 January 2016; Revised 14 May 2016; Accepted 5 June 2016

Academic Editor: Rita Gamberini

Copyright (c) 2016 Changfeng Zhu et al. This is an open access article distributed under the Creative Commons Attribution License, which permits unrestricted use, distribution, and reproduction in any medium, provided the original work is properly cited.

\begin{abstract}
In order to coordinate the complex relationship between supplies distribution and path selection, some influential factors must be taken into account such as the insufficient remaining capacity of the road and uncertainty of travel time during supplies distribution and transportation. After the structure of emergency logistics network is analyzed, the travel time Bayes risk function of path and the total loss Bayes risk function of the disaster area are proposed. With the emergency supplies total transportation unit loss as the goal, an emergency logistics network optimization model under crowded conditions is established by the Bayes decision theory and solved by the improved ant colony algorithm. Then, a case of the model is validated to prove that the emergency logistics network optimization model is effective in congested conditions.
\end{abstract}

\section{Introduction}

In the past ten years, nearly 9000 disasters have led to a great loss of property and casualties occurring in the world, on an average of about two new disasters every day [1]. Frequent natural disasters and other unexpected emergencies, especially like earthquakes, typhoons, floods, or other natural disasters, are not only a test of the government's emergency response but also a challenge for emergency logistics. However, during the process of planning, transporting, and storing, humanitarian logistics, unlike normal logistics, have their own unique characteristics [2] such as the large amount of material transportation, the uncertainty of vehicle routing, the urgency of the rescue time, and the randomness of abnormal congestion events.

In order to make effective plans, humanitarian logistics network designers need to collect information and make a provisional decision based on the existing information [3]. And with the development of disasters, the decision will be continuously adjusted to the current situation. Lodree Jr. and Taskin [4] introduced a stochastic inventory control problem and formulated it as an optimal stopping problem using Bayesian updates based on hurricane predictions.
Tofighi et al. [5] addressed a two-echelon humanitarian logistics network design problem and developed a novel two-stage scenario based possibility-stochastic programming (SBPSP) approach. However, there are many parameters that are difficult to quantify, making the humanitarian logistics optimization problem more complicated [6].

In the beginning of the disaster, as Özdamar and Balcik [7, 8] pointed out, traffic congestion will be heavier and it is easy to make traffic halted. Because of damaged roads and traffic congestion, common in disaster, section's remaining capacity decreases while the impedance increases. The sensitivity of section travel time for the additional traffic becomes higher and the uncertainty of the section travel time is increasing. Thus, it is very hard to select the path of humanitarian logistics and construct humanitarian logistics network. Here, in order to overcome the problem, the Bayes theory is introduced to formulate the travel time Bayes risk function of section, which is used to rationally quantify the travel time of section.

The uncertainty [5] exists not only in the path selection but also in the relief demands [8]. Ozdamar et al. [9, 10] pointed out that, because of the dynamics and uncertainties associated with various disaster characteristics, relief supplies 
are often available in limited quantities and precise relief demands are hard to rationally quantify during disaster. And there exists the game between affected areas [11, 12]. Each disaster area wants to get sufficient relief supplies, so the game will take place between affected areas. Furthermore, the different O-D distribution will lead to different forms of flow distribution in the transportation network [13]. So how to deal with the complex relationship between supplies distribution and path selection has become particularly important. In order to solve this problem, in consideration of the correlation between the total emergency loss and the delay of the emergency supplies, the total loss Bayes risk function of the disaster area is formulated. The total loss Bayes risk function consists of losses caused by the number of delayed relief supplies in the affected areas, which can reflect the effectiveness of emergency logistics network, and the losses of transportation time caused by real-time traffic condition, which can reflect the effectiveness of the travel time Bayes risk function.

Based on the total loss Bayes risk function, the emergency supplies total transportation unit loss is defined. With it as the goal, a multiperiod emergency logistics network optimization model under crowded conditions is established by employing multiperiod Bayesian decision theory, which can minimize the total loss Bayes risk function and the travel time Bayes risk function, and the dynamic user equilibrium (DUE) model [14], which makes full use of the remaining capacity of the road and minimizes transportation time [15]. Based on the model, an improved ant colony algorithm is proposed. And a case of the model is validated to prove that the emergency logistics networ optimization model is effective in congested conditions.

\section{Literature Review}

Optimization of emergency resources transportation network is a typical multipath selection problem under the influence of multifactors, such as the uncertainty of vehicle routing and the randomness of abnormal congestion events.

From the perspective of emergency logistics network, many scholars have made some researches on the optimization of emergency logistics network and some research achievements have been achieved. Aksen and Aras [16], Boloori Arabani and Farahani [17], and Farahani et al. [18] have studied the emergency facility location problem (FLP). Cosgrave [19] presented the three properties of emergency decision and used the Decision Participation Contingency Theory to construct a simple model of emergency decisionmaking process. Özdamar et al. [9] proposed a mixed multistage integer programming model which is solved by the Lagrangian Relaxation Technique. Pauwels et al. [20] explained the "irreversible effect" of decisions, which presented in economics research results, and applied the results to the withdrawal decision problems. Özdamar and Demir [7] described a hierarchical cluster and route procedure (HOGCR) for coordinating vehicle routing in large-scale postdisaster distribution and evacuation activities. Yong and Nan [21] had applied Bayesian analysis and optimization theory to establish emergency logistics system model which is solved by the genetic algorithms. Afshar and Haghani [22] had proposed a modeling integrated supply chain logistics in real-time large-scale disaster relief operations.

From the perspective of research methods, relevant scholars have studied this problem based on Bayesian theory; Zhan et al. [23] addressed multisupplier, multiaffected area, multirelief, and multivehicle relief allocation problem in disaster relief logistics. A multiobjective optimization model based on disaster scenario information updates is proposed in an attempt to coordinate efficiency and equity through timely and appropriate decisions regarding issues such as vehicle routing and relief allocation. Azoury [24] proposed a Bayesian solution to dynamic inventory models under unknown demand distribution conditions. Some relevant scholars also have studied this problem based on the network flow model [25], the game theory [26], scenario planning [27], and cooperative strategy [28, 29]. Existing research achievements have laid a certain foundation for this problem.

Nevertheless, optimization of emergency resources transportation network is complicated system engineering; there still are some facts that must be considered:

(1) Section, as the basic unit of emergency logistics network, has special traffic attributes. During disaster, the road capacity will decline and the travel time of section is highly sensitive for the additional traffic and varies with time under the congested or disordered conditions.

(2) The way of material distribution will affect the choices of vehicle routing. Because each disaster area wants to get sufficient relief supplies, the game will take place between affected areas. However, the different O-D distribution will lead to different forms of flow distribution in the transportation network [13]. So the way of material distribution will affect the choices of vehicle routing.

\section{The Analysis of Emergency Logistics Network Architecture}

Being a special logistics network, emergency logistics network is a complex network composed of a large number of sides (sections or paths) and node (logistics node). From complex network perspective, the emergency logistics transportation network has the characteristics of multinetwork and multilevel. Here, in order to fully understand the complex relationships between subnetworks of emergency logistics network, the emergency logistics network will be divided into three network layers: the actual road network, the disaster distribution network, and the emergency materials transportation network.

The actual road network is composed of many sections and transportation hubs, which is the basis of all transportation activities. The intersections or hubs are considered as nodes of the actual road network, while the sections between nodes are the edges of the actual road network. The actual road network is defined as $A-A$, whose edges have some characteristic value: the volume of traffic and length. So it 

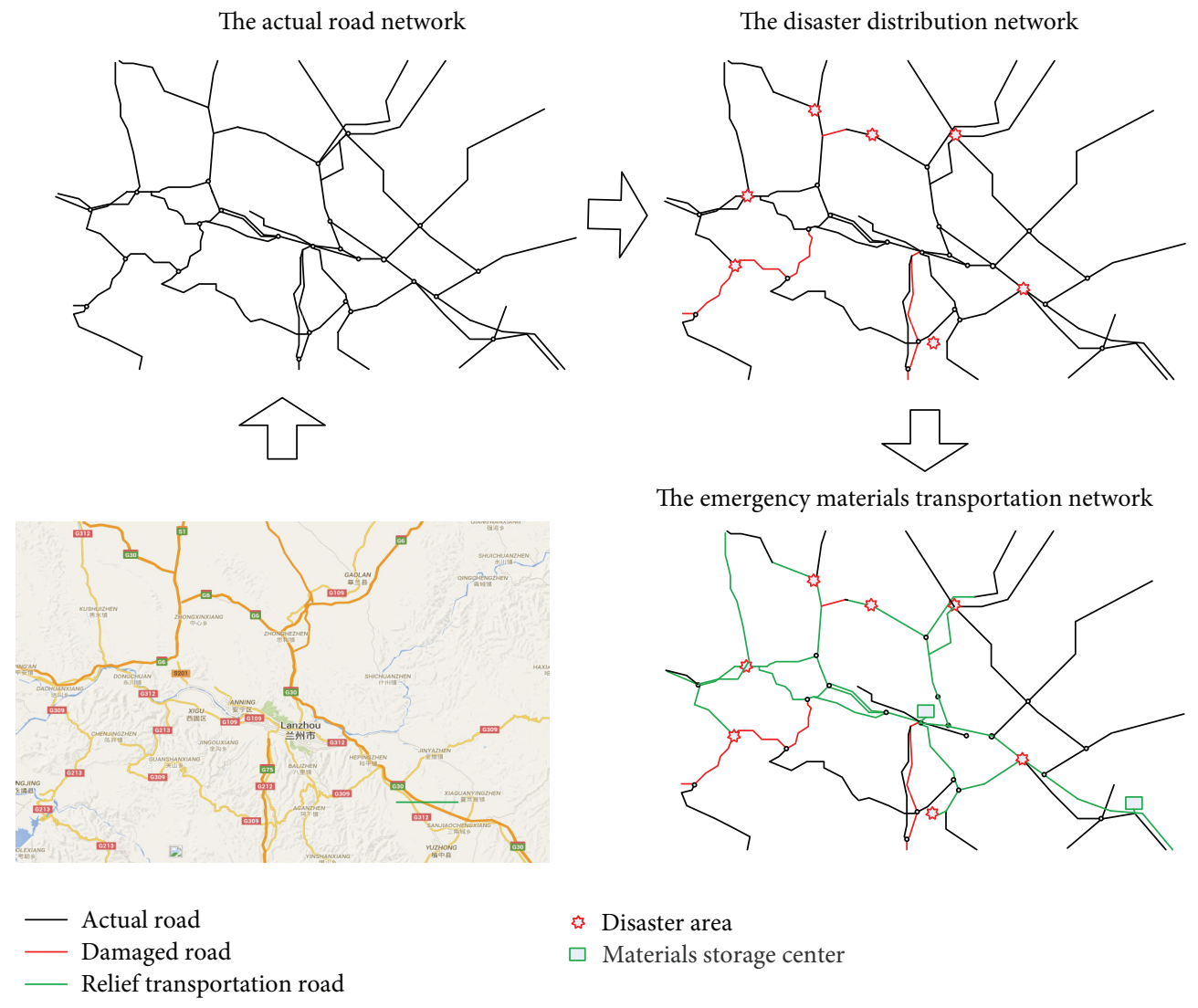

FIGURE 1: The flow chart of structuring emergency materials transportation network.

can be seen as a weighted network. $A-A$ network can be expressed as

$$
G_{A}=\left(A, E_{a-a}\right) \text {, }
$$

where $A=\left\{a_{1}, a_{2}, \ldots, a_{n}\right\}$ is a set of the actual road network nodes. $E_{a-a}=\left\{\left(a_{i}, a_{j}\right) \mid \theta\left(a_{i}, a_{j}\right)=\omega_{i j}\right.$ or 0$\}$ is the set of edges, while the design capacity $\theta\left(a_{i}, a_{j}\right)=\omega_{i j}$ is the weight of edges between $a_{i}$ and $a_{j} . \theta\left(a_{i}, a_{j}\right)=0$ means that there is no link between $a_{i}$ and $a_{j}$.

Assuming that the disaster information can be quantified and trusted, the disaster distribution network is composed of the damaged road and the demanded emergency supplies. The disaster distribution network is defined as $B-B$, whose network nodes are the disaster areas. The edges of the network are the road linking the disaster areas and emergency supplies storage center. $B-B$ network can be expressed as

$$
G_{b}^{t}=\left(B^{t}, E_{b-b}^{t}\right)
$$

where $B^{t}=\left\{b_{1}^{t}, b_{2}^{t}, \ldots, b_{n}^{t}\right\}$ is a set of the demanded quantity of supplies of each disaster area at stage $t . E_{b-b}^{t}=\left\{\left(a_{i}^{t}, a_{j}^{t}\right) \mid\right.$ $\left.\beta\left(a_{i}, a_{j}\right) \in[0,1]\right\}$ is a set of the section's remaining volume rate at stage $t$ (let the section's remaining volume rate be equal to the actual capacity/the designed road capacity $\omega_{i j}$ ). $\beta\left(a_{i}^{0}, a_{j}^{0}\right)=0$ means that there is no link between $a_{i}$ and $a_{j}$ or the section has been interrupted.
The emergency materials transportation network is a set of emergency materials transportation path, which is decided after taking the actual road network and the disaster distribution network into account. As shown in Figure 1, the planner refers to the actual road network and collects information about the damaged road and disaster distribution and then make a provisional decision about the relief transportation network. Since the disaster distribution will evolve over time $[3,4]$, the relief transportation network should include a variety of transportation solutions to adjust to the complex and changeable situation.

\section{Establishing Emergency Logistics Network Optimization Model}

4.1. Assumption. The Bayes Decision Method is the way of using the prior information and the sample information of the parameters to make decisions. Its prior information is based on the historical disaster information data. So consider the following assumptions.

Assumption 1. The disaster information can be quantified and trusted and the distribution of the disaster obeys a certain distribution. Thus, the prior distribution density functions $\pi\left(G_{b}^{0}\right)=(\theta, \gamma)$ of the damaged road distribution $\theta=$ $\left[\theta_{1}, \theta_{2}, \ldots, \theta_{n}\right]$ and the emergency supplies demand distribution $\gamma=\left\{\left(\theta_{i}, \theta_{j}\right) \mid \beta\left(\theta_{i}, \theta_{j}\right) \in[0,1]\right\}$ can be gotten from 
historical data. The sample distribution $G_{b}^{t}=\left(B^{t}, E_{b-b}^{t}\right)$ can be gotten from the relief information platform at $t$ periods. When the conditional density function of the emergency supplies demand distribution is $f_{t}\left(B^{t} \mid \theta\right)$, the conditional density function of the road damage distribution is $f_{t}\left(E_{b-b}^{t} \mid\right.$ $\gamma)$. So the posterior probability of the emergency supplies demand distribution is $\pi_{t}^{*}\left(\theta \mid B^{t}\right), t=1,2,3, \ldots$, and the posterior probability of the road damage distribution is $\pi_{t}^{*}\left(\gamma \mid E_{b-b}^{t}\right), t=1,2,3, \ldots$. Using the prior information and the sample information of the parameters, we can get the emergency supplies distribution plan $\delta^{t}$. And the emergency supplies distribution plan $\delta^{t}$ is composed of emergency supplies distribution plan $\delta^{t}\left(B^{t}\right)=\delta^{t}\left(b_{1}^{t}, b_{2}^{t}, \ldots, b_{n}^{t}\right)$ and evaluation values of each section's remaining volume rate $\delta^{t}\left(E_{b-b}^{t}\right)$ at $t$ periods.

Assumption 2. After having $\delta^{t}\left(B^{t}\right)$ and $\delta^{t}\left(E_{b-b}^{t}\right)$, the dynamic user equilibrium (DUE) model [16], which is known as $\mathrm{W}$-F model, is used to assign the traffic flow so that the transportation time is shortest. And the solution for this model had been given in reference [30]:

$$
\begin{aligned}
J=\min & \sum_{a \in A} \int_{0}^{T} \int_{0}^{x_{a}(t)} \xi_{a} c_{a}(\omega) d \omega d t \\
\text { s.t. } & x_{a}^{n}(t)=u_{a}^{n}(t)-\xi_{a} x_{a}^{n}(t) \\
& \forall a \in A, \forall n \in N, \forall t \in[0, T] \\
& \sum_{a \in A(m)} u_{a}^{n}(t)=q_{m n}(t)+\sum_{a \in B(m)} \xi_{a} x_{a}^{n}(t)
\end{aligned}
$$$$
\forall m \in N, \forall n \in N, \forall t \in[0, T], k \neq n
$$

$$
\begin{aligned}
& x_{a}^{n}(0)=x_{a}^{n, 0} \quad \forall a \in A, \forall n \in N \\
& u_{a}^{n}(t) \geq 0 \quad \forall a \in A, \forall n \in N, \forall t \in[0, T] .
\end{aligned}
$$

Assumption 3. The travel time of each section conforms to the US Federal Highway Administration impedance function model.

The function model is

$$
t_{a}=t_{0}\left[1+\alpha\left(\frac{V}{C}\right)^{\beta}\right]
$$

where $t_{a}$ is the travel time of section $a . t_{0}$ is the travel time of section $a$ when the traffic volume is zero. $V$ is the traffic volume of section $a . \alpha, \beta$ are parameters, and their recommended values are $\alpha=0.15, \beta=4$.

Because of damaged roads and traffic congestion, the section's travel time is increasing. Based on the DUE model, travel time $t_{a}\left(\delta^{t}\right)$ of section $a$ can be gotten under the emergency supplies distribution plan $\delta^{t}$. And $t_{a}\left(E_{b-b}^{t} \cdot E_{a-a}\right)$ is the additional time's expectations under road capacity changing. So the travel time of section at stage $t$ is

$$
t_{a}^{t}=t_{a}\left(\delta^{t}\right)+t_{a}\left(E_{b-b}^{t} \cdot E_{a-a}\right) .
$$

Assumption 4. Based on previous experience in disaster relief, early in the emergencies, the amount of total demand $c_{n}$ is more than the total material supplies $\sum_{m} y_{m n}^{t}$ in each batch. So the following holds

$$
\sum_{t} \sum_{m} y_{m n}^{t} \leq c_{n}
$$

4.2. The Travel Time Bayes Risk Function of Path $d$. Because secondary disasters lead to updated disaster distribution network, the sample distribution is also updated. According to the definition formula of Bayes risk function in reference [31], the travel time Bayes risk function of path $d$ is

$$
\begin{aligned}
r^{t}\left(\pi_{t}^{*}, \delta^{t}\right) & =E^{\pi_{t}^{*}\left(G_{b}^{t}\right)}\left[R^{t}\left(G_{b}^{t}, \delta^{t}\left(G_{b}^{t}\right)\right)\right]=E^{\pi^{*}\left(G_{b}^{t}\right)} \cdot t_{m n}^{d t} \\
& =\sum_{a \in d} E^{\pi^{*}\left(E_{b-b}^{t}\right)} \cdot E_{r^{t}}^{E_{b-b}^{t}} \cdot t_{m n}^{a d t}
\end{aligned}
$$

where $E^{\pi^{*}\left(E_{b-b}^{t}\right)}$ is the posterior probability density function expectation of $E_{b-b}^{t}$ at $t$ stage. $E_{\gamma^{t}}^{E_{b-b}^{t}}$ is the expectation when the observation value of sample distribution $\gamma^{t}$ is $E_{b-b}^{t} . t_{n m}^{a d t}$ is section $a$ travel time of path $d$ between $m$ and $n$ at $t$ th stage.

4.3. The Total Loss Bayes Risk Function of the Disaster Area. Here, the time threshold is being given. When the travel timeis more than the time threshold, it will be considered that the delay causing the loss will happen. So delayed time $\Delta t_{n}^{t}$ is as follows:

$$
\Delta t_{n}^{t}= \begin{cases}0 & r^{t}\left(\pi_{t}^{*}, \delta^{t}\right) \leq T_{m n}^{t} \\ r^{t} \cdot\left(\pi_{t}^{*}, \delta^{t}\right)-T_{m n}^{t} & r^{t}\left(\pi_{t}^{*}, \delta^{t}\right)>T_{m n}^{t}\end{cases}
$$

where $r^{t}\left(\pi_{t}^{*}, \delta^{t}\right)$ is the travel time of vehicles between $m$ and $n . T_{m n}^{t}$ is the time threshold of affected areas $n$.

As we all know, when supplies do not arrive in time, the property or life will be lost. Here, the transportation loss, which can reflect not only the delay time distribution but also the arrival rate of delayed supplies, is defined as the product of delayed time $\Delta t_{n}^{t}$ and the number of delayed supplies $c_{n}^{t}-$ $\sum_{m} y_{m n}^{t}$. This is shown in Figure 2.

According to the definition formula of Bayes risk function in reference [31], total transportation loss $Z$ Bayes risk function of the disaster area is as follows:

$$
Z=\sum_{n} \sum_{t} E^{\pi^{*}\left(B^{t}\right)} \cdot E_{\theta^{t}}^{B^{t}} \cdot \Delta t_{n}^{t} \cdot\left(c_{n}^{t}-\sum_{m} y_{m n}^{t}\right),
$$

where $E^{\pi^{*}\left(B^{t}\right)}$ is the posterior probability density function expectation of $B^{t}$ at $t$ stage. $E_{\theta^{t}}^{B^{t}}$ is the expectation when the observation value of sample distribution $\theta^{t}$ is $B^{t} . c_{n}^{t}$ is the total demanded amount of affected areas $n . y_{m n}^{t}$ is the supplied amount from supply point $m$ to affected areas $n$.

So emergency supplies total transportation unit loss $\eta$ of affected areas is as follows:

$$
\eta=\frac{\sum_{n} \sum_{t} E^{\pi^{*}\left(B^{t}\right)} \cdot E_{\theta^{t}}^{B^{t}} \cdot \Delta t_{n}^{t} \cdot\left(c_{n}^{t}-\sum_{m} y_{m n}^{t}\right)}{\sum_{t} \sum_{m} y_{m n}^{t}}
$$




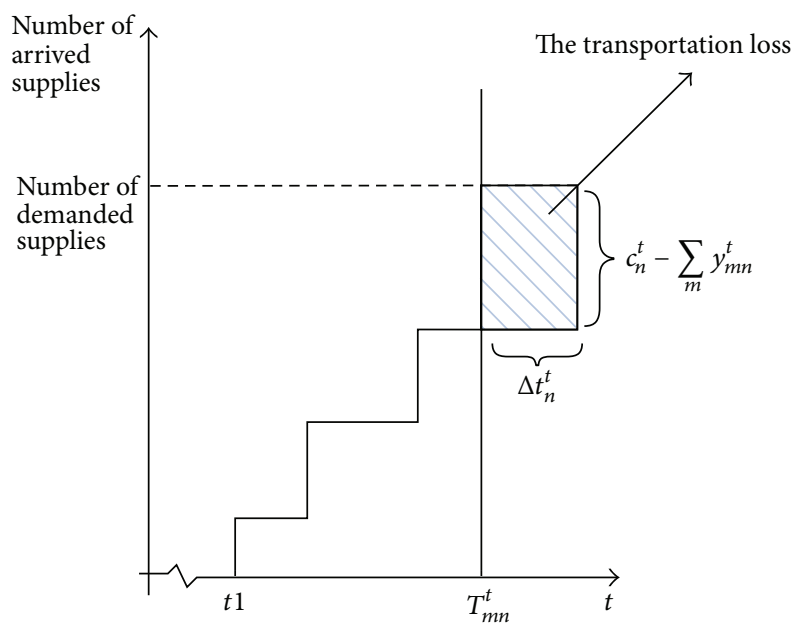

FIGURE 2: Time distribution of arrived supplies.

4.4. The Establishment of the Model. This model objective function is the minimal emergency supplies total transportation unit loss which is related to both the arrival time and the quantity of emergency supplies. According to Bayes theory, the emergency logistics network optimization model is established in congested conditions in $t$ stages.

The top model is

$$
\begin{aligned}
& \min \quad \eta=\frac{\sum_{n} \sum_{t} E^{\pi^{*}\left(B^{t}\right)} \cdot E_{\theta^{t}}^{B^{t}} \cdot \Delta t_{n}^{t} \cdot\left(c_{n}^{t}-\sum_{m} y_{m n}^{t}\right)}{\sum_{t} \sum_{m} y_{m n}^{t}} \\
& \sum_{t} \sum_{m} y_{m n}^{t} \leq c_{n} \\
& \Delta t_{n}^{t}= \begin{cases}0 & r^{t}\left(\pi_{t}^{*}, \delta^{t}\right) \leq T_{m n}^{t} \\
r^{t} \cdot\left(\pi_{t}^{*}, \delta^{t}\right)-T_{m n}^{t} & r^{t}\left(\pi_{t}^{*}, \delta^{t}\right)>T_{m n}^{t}\end{cases} \\
& t_{a}^{t}=t_{a}\left(\delta^{t}\right)+t_{a}\left(E_{b-b}^{t} * E_{a-a}\right) \\
& r^{t}\left(\pi_{t}^{*}, \delta^{t}\right)=\sum_{a \in d} E^{\pi^{*}\left(E_{b-b}^{t}\right)} \cdot E_{\gamma^{t}}^{E_{b-b}^{t}} \cdot t_{m n}^{a d t} .
\end{aligned}
$$

The lower model is

$$
\begin{array}{ll}
J=\min & \sum_{a \in A} \int_{0}^{T} \int_{0}^{x_{a}(t)} \xi_{a} c_{a}(\omega) d \omega d t \\
\text { s.t. } \quad & x_{a}^{n}(t)=u_{a}^{n}(t)-\xi_{a} x_{a}^{n}(t) \\
& \forall a \in A, \forall n \in N, \forall t \in[0, T] \\
& \sum_{a \in A(m)} u_{a}^{n}(t)=q_{m n}(t)+\sum_{a \in B(m)} \xi_{a} x_{a}^{n}(t) \\
\forall m \in N, \forall n \in N, \forall t \in[0, T], k \neq n \\
x_{a}^{n}(0)=x_{a}^{n, 0} \quad \forall a \in A, \forall n \in N \\
u_{a}^{n}(t) \geq 0 \quad \forall a \in A, \forall n \in N, \forall t \in[0, T],
\end{array}
$$

where $E^{\pi^{*}\left(B^{t}\right)}$ is the posterior probability density function expectation of $B^{t}$ at $t$ stage. $E_{\theta^{t}}^{B^{t}}$ is the expectation when the observation value of sample distribution $\theta^{t}$ is $B^{t} . c_{n}^{t}$ is the total demanded amount of affected areas $n$. $y_{m n}^{t}$ is the supplied amount from supply point $m$ to affected areas $n$. $r^{t}\left(\pi_{t}^{*}, \delta^{t}\right)$ is the section a travel time of vehicles between origin-destination $m$ and $n$. $T_{m n}^{t}$ is the time threshold value of affected areas $n . E^{\pi^{*}\left(E_{b-b}^{t}\right)}$ is the posterior probability density function expectation of $E_{b-b}^{t}$ at $t$ stage. $E_{\gamma^{t}}^{E_{b-b}^{t}}$ is the expectation when the observation value of sample distribution $\gamma^{t}$ is $E_{b-b}^{t} . t_{n m}^{a d t}$ is section $a$ travel time of path $d$ between origindestination $m$ and $n$ at $t$ stage. $t_{a}^{t}$ is the actual time of section $a$ at $t$ stage. $t_{i j}\left(\delta^{t}\right)$ is the travel time under the emergency supplies distribution plan. $t_{i j}\left(E_{b-b}^{t} * E_{a-a}\right)$ is the additional time under road capacity changing.

\section{The Algorithm Design}

Since the optimization problem is NP-hard problems and cannot be converted by polynomial or linear programming to solve, the ant colony algorithm is used to solve this problem in this paper. There are two main phases that the ant colony algorithm is comprised of: the ant's solution construction and the pheromone update [32]. To solve the problems of the model, the ant colony algorithm calculation is modified to adapt to it.

(1) The ant's solution construction: before the path selection, the prior distribution of both the section's remaining volume rate and the supplies demanded quantity of each disaster area is evaluated. Here, each affected area is considered as attractor with different attract strength. According to the principle of greedy algorithm, each ant pursuits the highest unit value of food, which means that attraction strength $Q_{n}$ is directly proportional to stock losses $p_{m n}^{t}$ in affected area $n$ and inversely proportionate to transport distance $L_{m n}$ from affected area to emergency materials storage center. Initial pheromone $\tau_{a}(0)$ of sections of $a$ is as follows:

$$
\tau_{a}(0)=\frac{t_{a}(0)}{\sum_{a} t_{a}(0)}+\frac{p_{m n}^{t}(0) \cdot \sum_{n} L_{m n}(0)}{\sum_{n} p_{m n}^{t}(0) \cdot L_{m n}(0)} \alpha_{m n}^{a d} .
$$

The probability of selection $p_{i j}^{k}(t)$ from node $i$ to node $j$ can be defined as follows:

$$
p_{i j}^{k}(t)=\frac{\tau_{i j}^{\alpha}(t) \times \eta_{i j}^{\beta}(t)}{\sum_{j \in \operatorname{tabu}_{k}} \tau_{i j}^{\alpha}(t) \times \eta_{i j}^{\beta}(t)},
$$

where $\tau_{i j}(t)$ is the pheromone strength in edge $(i, j), \eta_{i j}(t)$ is a heuristic value that is available a priori, $\alpha, \beta$ are two parameters which determine the relative influence of the pheromone trail and the heuristic information, and tabu $u_{k}$ is the tabu table. 
TABLE 1: Each section travel time under normal conditions.

\begin{tabular}{|c|c|c|c|c|c|c|c|c|c|c|c|c|c|c|c|c|c|}
\hline Section & A & B & C & $\mathrm{D}$ & E & $\mathrm{F}$ & G & $\mathrm{H}$ & I & $\mathrm{J}$ & K & $\mathrm{L}$ & M & $\mathrm{N}$ & $\mathrm{O}$ & $\mathrm{P}$ & Q \\
\hline$t_{0} /(\mathrm{h})$ & 2.1 & 2.3 & 1.4 & 3.4 & 2.4 & 3.4 & 2.5 & 2.2 & 2.7 & 4.1 & 2.8 & 1.3 & 2.4 & 3.6 & 2.3 & 1.5 & 3.4 \\
\hline
\end{tabular}

TABLE 2: The observed value of the section's remaining volume rate.

\begin{tabular}{|c|c|c|c|c|c|c|c|c|c|c|c|c|c|c|c|c|c|}
\hline Stage & A & B & C & D & $\mathrm{E}$ & $\mathrm{F}$ & G & $\mathrm{H}$ & I & $\mathrm{J}$ & $\mathrm{K}$ & $\mathrm{L}$ & $\mathrm{M}$ & $\mathrm{N}$ & $\mathrm{O}$ & $\mathrm{P}$ & Q \\
\hline 1 & 0.4 & 0.3 & 0.4 & 0.2 & 0.3 & 0.2 & 0.2 & 0.1 & 0.2 & 0.3 & 0.4 & 0.4 & 0.4 & 0.5 & 0.2 & 0.3 & 0.3 \\
\hline 2 & 0.5 & 0.4 & 0.3 & 0.4 & 0.3 & 0.1 & 0.2 & 0.2 & 0.2 & 0.2 & 0.1 & 0.2 & 0.5 & 0.3 & 0.2 & 0.4 & 0.3 \\
\hline
\end{tabular}

TABLE 3: The observed value of the demand for materials in the affected area.

\begin{tabular}{lcccccccc}
\hline Stages & 1 & 2 & 3 & 4 & 5 & 6 & 7 & 5 \\
\hline $1 /$ pcu & 56 & 86 & 89 & 56 & 78 & 57 & 56 & 79 \\
$2 /$ pcu & 47 & 57 & 67 & 74 & 46 & 35 & 34 & 56 \\
\hline
\end{tabular}

(2) The pheromone update: in order to simulate the pheromone evaporation phenomenon, the pheromone update is as follows:

$$
\tau_{i j}(t)=(1-\rho) \times \tau_{i j}(t)+\rho \times \sum_{k} \Delta \tau_{i j}^{k}(t),
$$

$$
\rho \in(0,1)
$$

where $\rho$ is the volatile factor of pheromone and $\Delta \tau_{i j}^{k}$ is the remaining pheromone of $k$ th ant. Because the Bayes decision theory is introduced, the pheromone density ratio of each road can be adjusted according to the posterior information:

$$
\Delta \tau_{i j}^{k}=C \cdot P\left(\frac{A_{j}}{B}\right)=C \cdot \frac{P\left(A_{j}\right) P\left(B / A_{j}\right)}{\sum_{i=1}^{n} P\left(A_{i}\right) P\left(B / A_{i}\right)},
$$

where $C$ is the pheromone's density value on each path at initialization phase. $P\left(A_{i}\right)$ is the ratio of $i$ th successor route pheromones and the total pheromone on all successor route. And $P\left(B / A_{i}\right) \in[0.5,1]$. Supposing there are $n$ successor routes, when $j$ th successor route is selected, $P\left(B / A_{i}\right)$ can be gotten as follows:

$$
P\left(\frac{B}{A_{i}}\right)= \begin{cases}1-\frac{L_{j}}{2 \max L} & i=j \\ 0.5 & i \neq j\end{cases}
$$

where $\max L$ is the maximum length of routes.

\section{Case Study}

In this section, we provide details of the case study for the emergency logistics network optimization model to optimize the transportation network of emergency materials aiming at better response to the relief work for the earthquake. Here, take the Wenchuan Earthquake as a case. The Wenchuan Earthquake affected 47,789 villages and 4,656 towns in Sichuan, Gansu, Shanxi, and Chongqing provinces [33]. In order to simplify the calculation and prove the model, we only

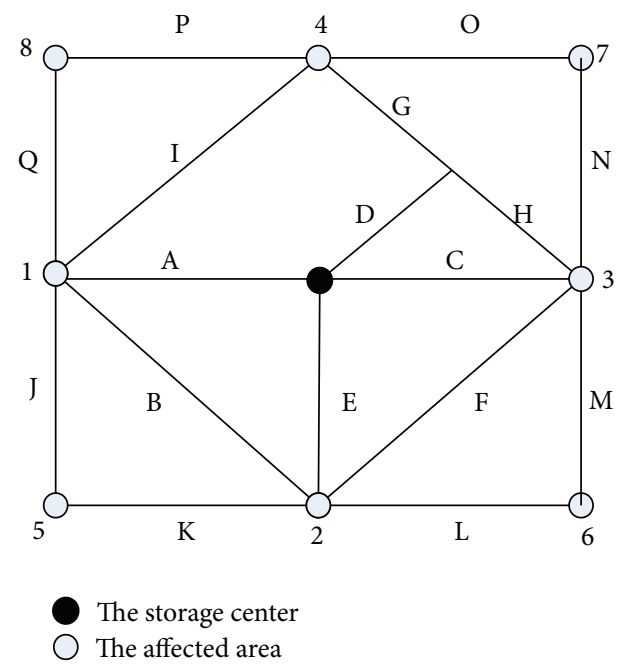

FIGURE 3: The emergency materials storage center and the affected area network distribution map.

consider a storage center located in Chengdu, which allocates supplies to the affected areas. The simplified structure diagram is as shown in Figure 3.

The supplies quantity of emergency supplies storage center is 973 . Under normal condition, each section travel time $t_{0}$ can be found in Table 1 . The observed value of the demanded supplies in the affected areas and the section's remaining volume rate can be gotten from the national disaster reduction center as in Tables 2 and 3. Time threshold of affected area $n$ can be found in Table 4 .

(1) The Prior Distribution. We can get the prior information of the disaster distribution network and the affected population from China's national disaster reduction center database [33]. The prior distribution of the demanded materials in the affected area is normal distribution $\theta^{t} \sim N(53,246)$. It is a pity that the prior distribution of damaged roads cannot be gotten. According to disaster relief experience, we assume 
TABLE 4: Time threshold of affected area $n$.

\begin{tabular}{lcccccccc}
\hline The affected area & 1 & 2 & 3 & 4 & 5 & 6 & 7 & 8 \\
Time threshold $T_{n} /(\mathrm{h})$ & 1.92 & 2.57 & 1.02 & 5.24 & 5.34 & 3.22 & 4.62 & 5.21 \\
\hline
\end{tabular}

TABLE 5: Comparison of the average transportation time before and after optimization.

\begin{tabular}{lcccccccc}
\hline & 1 & 2 & 3 & 4 & 5 & 6 & 7 \\
\hline After optimization & 2.39 & 2.74 & 1.53 & 6.21 & 6.36 & 3.97 & 5.32 & 5.84 \\
Before optimization & 2.42 & 3.21 & 1.89 & 7.23 & 7.59 & 4.18 & 6.42 & 6.73 \\
\hline
\end{tabular}

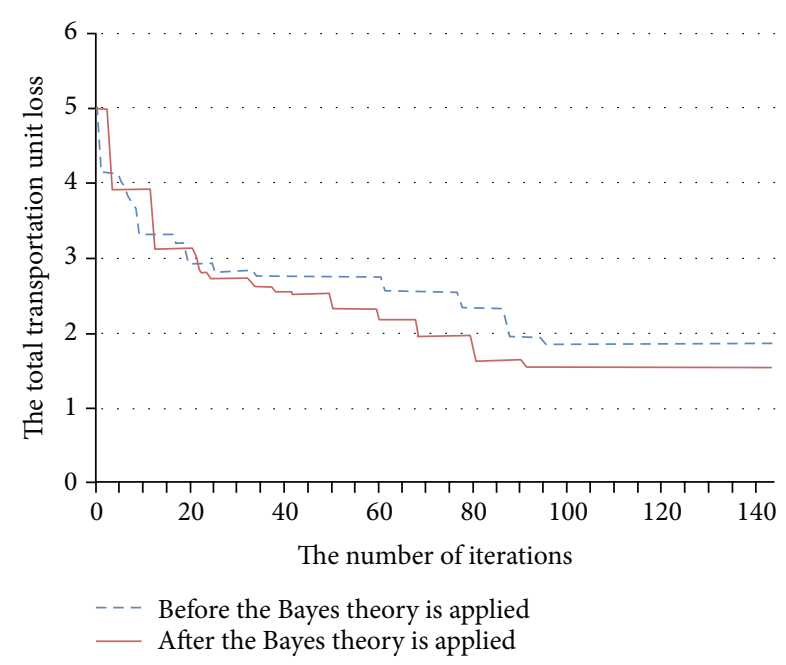

FIgURE 4: The total transportation unit loss.

that the section remaining volume rate's prior distribution is normal distribution $\beta_{i j}^{t} \sim N(0.24,0.16)$.

(2) The Simulation Results and Analysis. The simulation program is written in $\mathrm{C}++$ program. Before and after the Bayes theory is applied, the simulation convergence figures of emergency supplies total transportation unit loss are shown in Figure 3 and the average transport time of eight affected areas is shown in Figure 4 and Table 5.

Comparison of the average transportation time before and after optimization is shown in Table 5.

By comparing the results before and after the Bayes theory is applied, we can find from Figures 3 and 4 and Table 5 that total transportation unit loss and average transport time have decreased, which has proved that it is effective in introducing the Bayes theory to optimize the emergency supplies transportation in this model. From Figure 3, it is obvious that the convergence speed of the ant algorithm is improved after introducing the Bayes theory which is consistent with the result of the paper [34].

\section{Conclusions}

At the beginning of the disaster, especially large-scale disasters such as earthquakes, the demanded emergency supplies often increases dramatically. But there often exists shortage

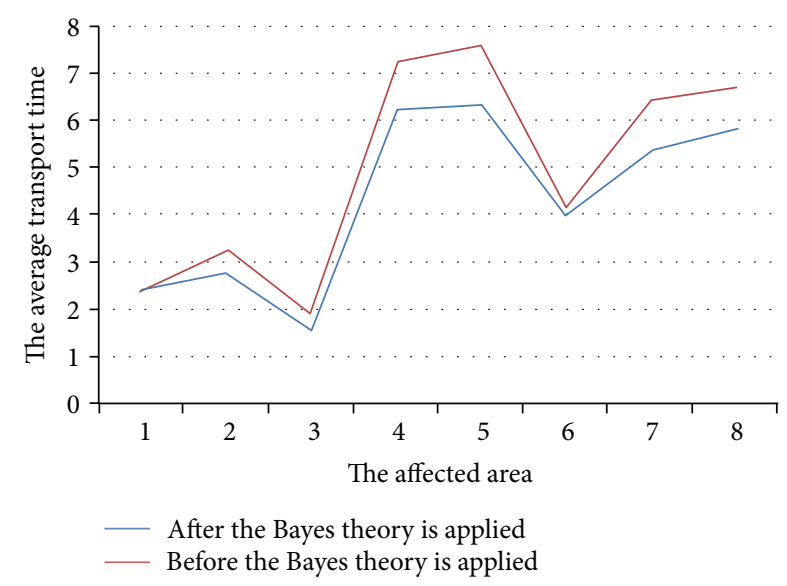

FIgURE 5: The average transportation time of eight affected areas.

or delay of supplies. The road transport network is also extremely crowded because of the damaged roads and the disorderly traffic. In this paper, we take emergency logistics network as the research object and study it deeply; the research conclusions are the following.

(1) Analysis of the structure of emergency logistics network: in this paper, the emergency logistics network is divided into three network layers: the actual road network, the disaster distribution network, and the emergency materials transportation network. That fully demonstrates the inherent relationship between every emergency logistics network subnet.

(2) Based on Bayesian decision, a double emergency logistics network optimization model is established in the paper. In the top model, some factors, the uncertainty of the travel time and time threshold, are considered. In the lower model, the dynamic user equilibrium (DUE) model is used to assign the traffic flow so that the transportation time is shortest. In this process, both the travel time Bayes risk function of section and the total loss Bayes risk function of the disaster area are constructed, which effectively solves the uncertain problem of material distribution and path selection.

(3) It is effective in applying Bayesian decision theory to optimize emergency logistics. Comparing the results before and after the Bayes theory is applied, we can find that the average transport time of eight affected areas shows different degrees of decline (Figure 5). It means that it is effective 
in introducing the Bayes theory to optimize the emergency supplies transportation in this model. Comparing emergency supplies total transportation unit loss before and after the Bayes theory is applied proves that introducing the Bayes theory is helpful in optimizing the ant algorithm and the emergency supplies transportation.

\section{Competing Interests}

The authors declare that there are no competing interests regarding the publication of this paper.

\section{Acknowledgments}

This work is supported by The National Nature Science Foundation of China (no. 61364028), The Natural Science Foundation of Gansu Province of China (no. 1508RJZA061), The Chinese Ministry of Education of Humanities and Social Science Project (no. 15XJAZH002), and The University Scientific Research Project of Gansu Province of China (no. 2014A-047).

\section{References}

[1] F. Liberatore, M. T. Ortuño, G. Tirado, B. Vitoriano, and M. P. Scaparra, "A hierarchical compromise model for the joint optimization of recovery operations and distribution of emergency goods in Humanitarian Logistics," Computers and Operations Research, vol. 42, pp. 3-13, 2014.

[2] D. G. Kovács and K. M. Spens, "Humanitarian logistics in disaster relief operations," International Journal of Physical Distribution \& Logistics Management, vol. 37, no. 2, pp. 99-114, 2007.

[3] B. Balcik and B. M. Beamon, "Facility location in humanitarian relief," International Journal of Logistics Research and Applications, vol. 11, no. 2, pp. 101-121, 2008.

[4] E. J. Lodree Jr. and S. Taskin, "Supply chain planning for hurricane response with wind speed information updates," Computers \& Operations Research, vol. 36, no. 1, pp. 2-15, 2009.

[5] S. Tofighi, S. A. Torabi, and S. A. Mansouri, "Humanitarian logistics network design under mixed uncertainty," European Journal of Operational Research, vol. 250, no. 1, pp. 239-250, 2016.

[6] B. Beamon and S. Kotleba, "Inventory modelling for complex emergencies in humanitarian relief operations," International Journal of Logistics Research and Applications, vol. 9, no. 1, pp. 1-18, 2006.

[7] L. Özdamar and O. Demir, "A hierarchical clustering and routing procedure for large scale disaster relief logistics planning," Transportation Research Part E: Logistics and Transportation Review, vol. 48, no. 3, pp. 591-602, 2012.

[8] B. Balcik, B. M. Beamon, and K. Smilowitz, "Last mile distribution in humanitarian relief," Journal of Intelligent Transportation Systems: Technology, Planning, and Operations, vol. 12, no. 2, pp. 51-63, 2008.

[9] L. Özdamar, E. Ekinci, and B. Küçükyazici, "Emergency logistics planning in natural disasters," Annals of Operations Research, vol. 129, pp. 217-245, 2004.

[10] W. Yi and L. Özdamar, "A dynamic logistics coordination model for evacuation and support in disaster response activities,"
European Journal of Operational Research, vol. 179, no. 3, pp. 1177-1193, 2007.

[11] R. S. Shetty, An event driven single game solution for resource allocation in a multi-crisis environment [Ph.D. thesis], University of South Florida, Tampa, Fla, USA, 2004.

[12] U. Gupta, Multi-event crisis management using non-cooperative repeated games [Ph.D. thesis], University of South Florida, 2004.

[13] Z. Zhang, Z. Hao, and Z. Gao, "A dynamic adjustment and distribution method of air traffic flow en-route," Journal of Air Transport Management, vol. 42, pp. 15-20, 2015.

[14] T. L. Friesz, D. H. Bernstein, T. E. Smith, R. L. Tobin, and B.W. Wie, "A variational inequality formulation of the dynamic network user equilibrium problem," Operations Research, vol. 41, no. 1, pp. 179-191, 1993.

[15] M. Amirgholy and E. J. Gonzales, "Demand responsive transit systems with time-dependent demand: user equilibrium, system optimum, and management strategy," Transportation Research Part B: Methodological, 2015.

[16] D. Aksen and N. Aras, "A bilevel fixed charge location model for facilities under imminent attack," Computers \& Operations Research, vol. 39, no. 7, pp. 1364-1381, 2012.

[17] A. Boloori Arabani and R. Z. Farahani, "Facility location dynamics: an overview of classifications and applications," Computers \& Industrial Engineering, vol. 62, no. 1, pp. 408-420, 2012.

[18] R. Z. Farahani, M. Hekmatfar, B. Fahimnia, and N. Kazemzadeh, "Hierarchical facility location problem: models, classifications, techniques, and applications," Computers \& Industrial Engineering, vol. 68, no. 1, pp. 104-117, 2014.

[19] J. Cosgrave, “Decision making in emergencies," Disaster Prevention and Management, vol. 5, no. 4, pp. 28-35, 1994.

[20] N. Pauwels, B. Van De Walle, F. Hardeman, and K. Soudan, "The implications of irreversibility in emergency response decisions," Theory and Decision, vol. 49, no. 1, pp. 25-51, 2000.

[21] Y. Yong and L. Nan, "Information update based sequential approach for emergency resources allocation planning," Journal of Zhejiang University: Engineering Science, vol. 35, no. 12, pp. 2212-2220, 2013.

[22] A. Afshar and A. Haghani, "Modeling integrated supply chain logistics in real-time large-scale disaster relief operations," Socio-Economic Planning Sciences, vol. 46, no. 4, pp. 327-338, 2012.

[23] S.-L. Zhan, N. Liu, and Y. Ye, "Coordinating efficiency and equity in disaster relief logistics via information updates," International Journal of Systems Science, vol. 45, no. 8, pp. 16071621, 2014.

[24] K. S. Azoury, "Bayes solution to dynamic inventory models under unknown demand distribution," Management Science, vol. 31, no. 9, pp. 1150-1160, 1985.

[25] A. Haghani and S.-C. Oh, "Formulation and solution of a multicommodity, multi-modal network flow model for disaster relief operations," Transportation Research Part A: Policy and Practice, vol. 30, no. 3, pp. 231-250, 1996.

[26] U. Gupta, Multi-event crisis management using non-cooperative repeated games [Ph.D. dissertation], University of South Florida, 2004.

[27] M.-S. Chang, Y.-L. Tseng, and J.-W. Chen, "A scenario planning approach for the flood emergency logistics preparation problem under uncertainty," Transportation Research Part E: Logistics and Transportation Review, vol. 43, no. 6, pp. 737-754, 2007. 
[28] Y. Sha and J. Huang, "The multi-period location-allocation problem of engineering emergency blood supply systems," Systems Engineering Procedia, vol. 5, pp. 21-28, 2012.

[29] F. Barzinpour and V. Esmaeili, "A multi-objective relief chain location distribution model for urban disaster management," The International Journal of Advanced Manufacturing Technology, vol. 70, no. 5-8, pp. 1291-1302, 2014.

[30] T. L. Friesz, D. Bernstein, T. E. Smith, R. L. Tobin, and B.-W. Wie, "A variational inequality formulation of the dynamic network user equilibrium problem," Operations Research, vol. 41, no. 1, pp. 179-191, 1993.

[31] Berfer J O, Statistical Decision Theory and Bayesian Analysis, Springer, New York, NY, USA, 1980.

[32] M. Dorigo and T. Stützle, Ant Colony Optimization, MIT Press, Cambridge, Mass, USA, 2004.

[33] UNCRD, Reconnaissance Report of the 2008 Sichuan Earthquake, Japanese Edition, 2009.

[34] W. Yiqing and S. Aiguo, "Ant colony optimal algorithms based on Bayes decision," Journal of Southeast University: Natural Science Edition, vol. 35, no. 4, pp. 558-562, 2005. 


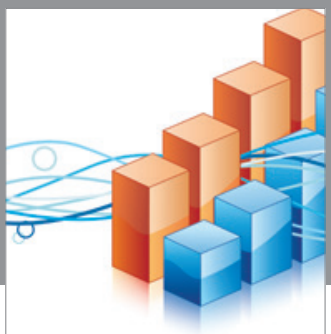

Advances in

Operations Research

vatem alat4

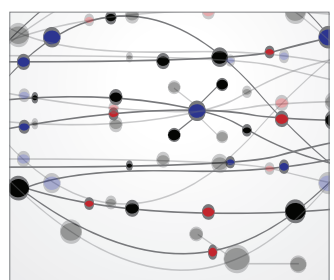

\section{The Scientific} World Journal
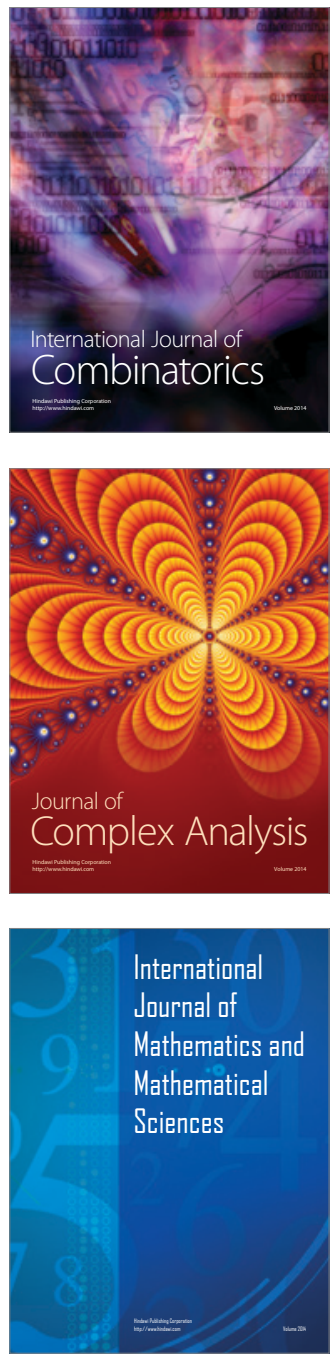
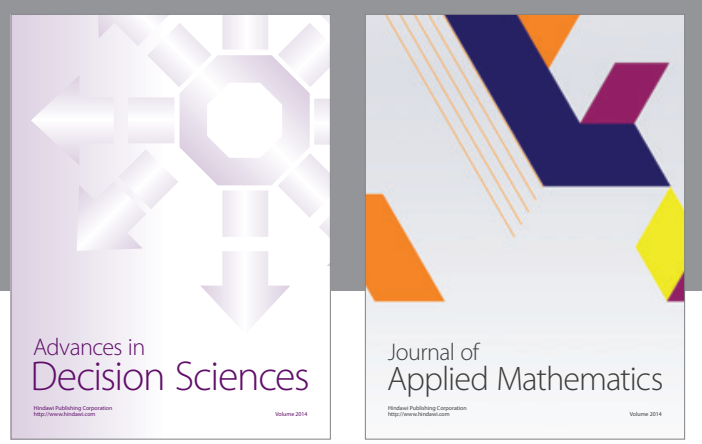

Algebra

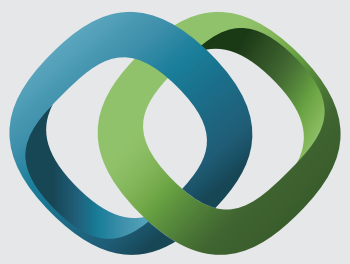

\section{Hindawi}

Submit your manuscripts at

http://www.hindawi.com
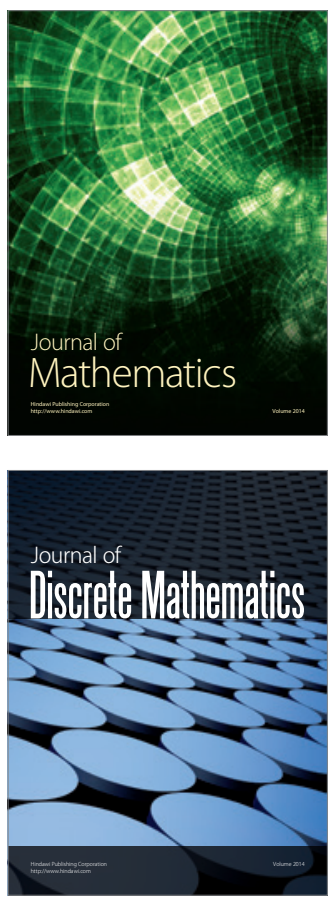

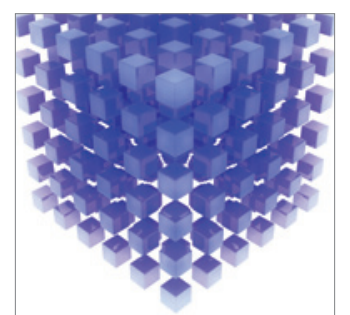

Mathematical Problems in Engineering
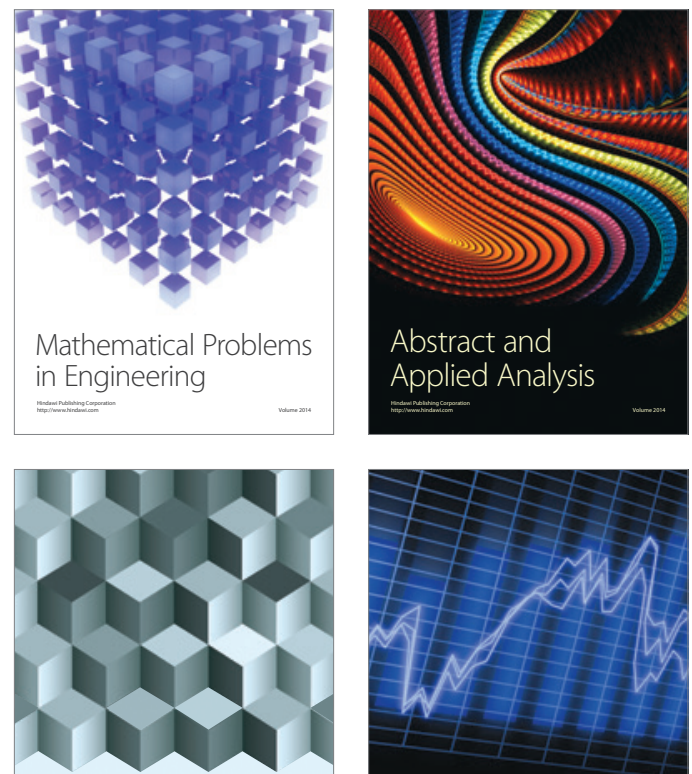

Journal of

Function Spaces

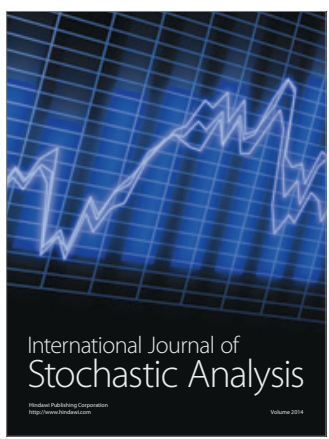

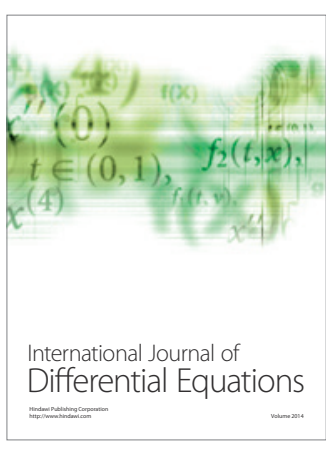
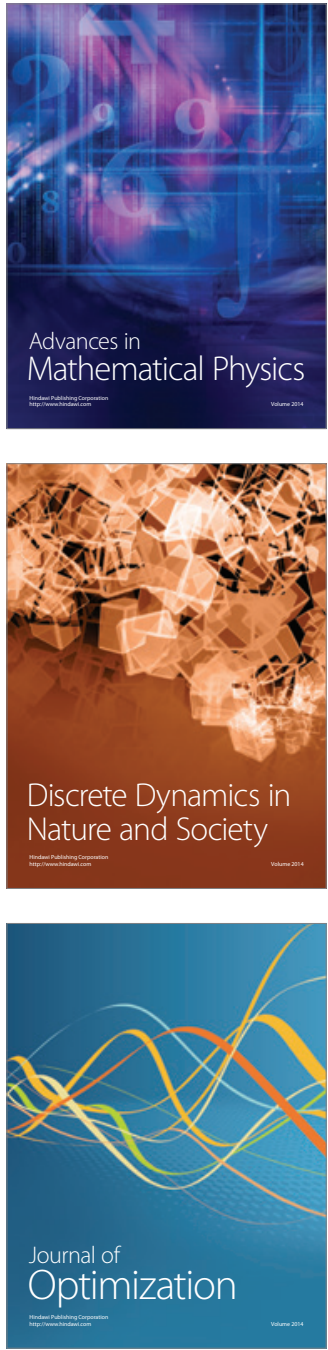